\title{
The low and high postpubertal ethanol use: long-term effects on drinkers' reproductive parameters and ethanol-naive offspring development
}

Vanessa Caroline Fioravante ${ }^{1}$, Alana Rezende Godoi ${ }^{1}$, Victória Mokarzel de Barros

Camargo $^{1}$, Patricia Fernanda Felipe Pinheiro ${ }^{1}$, Marcelo Martinez ${ }^{2}$, Carlos Roberto Padovani $^{3}$, Francisco Eduardo Martinez ${ }^{1}$

${ }^{1}$ Department of Structural and Functional Biology, Institute of Biosciences of Botucatu (IBB), UNESP - Univ Estadual Paulista, São Paulo, Brazil

${ }^{2}$ Department of Morphology and Pathology, Univ Federal de São Carlos (UFSCar), São Carlos, Brazil

${ }^{3}$ Department of Biostatistics, Institute of Biosciences of Botucatu (IBB), UNESP - Univ Estadual Paulista, São Paulo, Brazil

Corresponding author: Francisco Eduardo Martinez

Adress: Institute of Biosciences of Botucatu (IBB), UNESP - Univ Estadual Paulista, PO Box 510, Postal Code 18618-970, Botucatu, São Paulo State, Brazil

Phone: +55 (14) 3880-0024

Email: fe.martinez@unesp.br 


\begin{abstract}
The relationship between adolescent ethanol uses and its impacts throughout life is not conclusive. Thus, we evaluated if the low and high consumption of ethanol during the postpuberty period interferes with reproduction in adulthood, the ethanol-naive offspring development and if there are dose-related effects. Females and males' rats were divided into three groups: low drinker (L), with UChA rats fed with ethanol ad libitum drinking $<1.9 \mathrm{~g} / \mathrm{kg} / \mathrm{day}$, high drinker $(\mathrm{H})$, with UChB rats fed with ethanol ad libitum drinking from 2 to $5 \mathrm{~g} / \mathrm{kg} /$ day, and control (C), with rats without access to ethanol. The $\mathrm{L}$ and $\mathrm{H}$ groups were exposed to ethanol 10\% (v/v) from 65 to 80 days, with withdrawal after this period. The study was conducted in two phases. The retrospective analysis (1st phase) verified the consumption of ethanol between sexes, the litter size, and the sex ratio of offspring. The gestational and reproductive parameters of parents and the development of pups were analyzed in the 2 nd phase. We observed a higher consumption of ethanol in females and a reduced litter size in both drinkers' groups. Body weight gain and gestational feed consumption were lower in $\mathrm{L}$ and $\mathrm{H}$. The offspring's body weight was also lower associated with alteration in landmarks of physical development. The high postpubertal ethanol use accents the impacts on consumers and offspring. The paternal and maternal reproductive organs weight was altered in group $\mathrm{H}$, with an increase in morphologically abnormal sperm. We conclude that low and high post-pubertal alcohol consumption impairs reproductive parameters, even after withdrawal with long-term effects. Ethanol-naive offspring are also harmed, with effects associated with the dose of ethanol.
\end{abstract}

Keywords: alcohol; abstinence; preconception; reproduction; offspring; litter size; development; UCh. 


\section{Introduction}

Ethanol is one of the main abuse drugs ingested worldwide (Rehm et al. 2009, Balddin et al. 2018) and responsible for approximately $5.2 \%$ of global deaths (GBD 2018). Alcohol use prevails among the young and adults with more than 76 million people diagnosed with alcohol-related disorders (Ghazali \& Patel 2016; Harding et al. 2016). The implications of consumption need to consider the age, the amount ingested and the consumers' individual characteristics (HHS 2005, Balddin et al. 2018).

Approximately $15 \%$ of couples show signs of infertility (Sharlip et al. 2002; Barazani et al., 2014), being the daily habits, including diet and exposure to toxicants, could modulate reproductive health (Asimes et al. 2018). The ethanol is a toxic agent that disturbs the integrity of biochemical and physiological functions and the development of structures involved in reproduction, causing severe damage to the signaling of hypothalamic-pituitary-gonadal / adrenal axes (HPG/HPA) (Wallock-Montelius et al. 2007). This way, alcohol intake can result in female and male reproductive pathologies confirmed in experimental models (Oremosu \& Akang 2015, Srivastava et al. 2018) and humans (Eggert et al. 2004, Sansone et al. 2018) since ethanol could lead to lower sperm quality and ovulatory irregularities (Sengupta et al. 2017). Besides, ethanol-induced epigenetic mechanisms can modify the expression pattern of different tissues on drinkers, as well as is the major mechanism related to descendants' phenotypes alterations (Asimes et al. 2017).

Studies highlight that heavy drinker on gestation can reduce litter size, increase mortality rate, and impair the offspring, however, regarding the sex ratio, the results are inconclusive (Anderson et al. 1978, Cicero et al. 1994, Vaglenova \& Petkov 1998, Liang et al. 2014, Gardebjer et al. 2014). Although high alcoholic use has greater effects on reproduction, low to moderate intake has been still under discussion, requiring constant research (Sansone et al. 2018, Barazani et al., 2014). It found in rodents that prepuberty and preconception ethanol exposure can also be harmful to drinkers and their pups, nevertheless, there is no knowledge about the postpuberty period. Thus, studies that aim to verify postpubertal ethanol and its effects on reproduction can help to elucidate the degree of damages of early ethanol intake and the mechanisms behind it. In order to it, we employed the UCh rats, a voluntary ethanol-drinking model derived from original Wistar rats (Mardones \& SegoviaRiquelme 1983). This strain represents a special model for understanding the basis of alcoholism-linked characteristics. We hypothesized that 
the high and low ethanol-drinking on postpuberty negatively influences the parameters of reproduction in adulthood, even after ethanol withdrawal, and affects the ethanol-naive offspring, with dose-related effects. This way, we evaluated whether the low and high ethanol impairs drinkers' body weight, litter size and sex ratio offspring, the ethanol-naive offspring development, and parents' reproductive parameters. Part of this study was carried out by a collection of data over ten years, allowing us to assess different generations.

\section{Material and methods}

\section{Animals and experimental design}

The experiments were in accordance with the Ethical Principles in Animal Research and approved by the Bioscience Institute / UNESP Ethical Committee for Animal Research (protocol $\mathrm{n}^{\circ}$ 051/04). Female (171 $\left.\pm 6.3 \mathrm{~g}\right)$ and male $(231 \pm 10.7 \mathrm{~g}$ ) rats (Rattus norvegicus albinus) at 55 days old obtained from the Department of Structural and Functional Biology of Botucatu Bioscience Institute / UNESP were used. The rats were divided into three groups: low drinker (L) constituted by UChA rats, high drinker (H) constituted by UChB rats and control rats $(\mathrm{C})$ without access to ethanol. The low and high ethanol-drinking animals were fed with 1:10 (v/ v) ethanol ad libitum (free choice for water or ethanol) while control animals were fed only water. The ethanol-drinking groups, L and $\mathrm{H}$, were exposed to ethanol for 15 consecutive days for voluntary consumption. Thus, free access of 1:10 (v/v) ethanol solution was provided for them from post-natal day (PND) 65 to 80, corresponding to postpuberty (Picut et al. 2015). Ethanol was withdrawn after this period. The UChA rats consume a low amount of ethanol, drinking from 0.1 to $1.9 \mathrm{~g} / \mathrm{kg} / \mathrm{day}$, and $\mathrm{UChB}$ rats consume a high amount of ethanol, drinking from 2.0 to $6.0 \mathrm{~g} / \mathrm{kg} / \mathrm{day}$. Only animals with the adequate consumption profile (low and high ethanol consumption) were selected to continue in the experiment (Mardones \& Segovia-Riquelmi 1983). After the selection process of drinkers' animals from $\mathrm{L}$ and $\mathrm{H}$ groups, they were alcohol withdrawal to mating. Females of $\mathrm{C}, \mathrm{L}$, and $\mathrm{H}$ groups were mating to males of $\mathrm{C}, \mathrm{L}$, and $\mathrm{H}$, respectively, at 100 days old.

The animals were housed in polypropylene cages $(32 \mathrm{~cm} \times 40 \mathrm{~cm} \times 18 \mathrm{~cm})$ and maintained under controlled conditions $\left(25 \pm 1{ }^{\circ} \mathrm{C}\right.$, humidity $55 \pm 5 \%$, and light from 6 to $18 \mathrm{~h}$ ) with access to commercial feed and water ad libitum. In this study, we employed 
a voluntary model of ethanol exposure, UCh rats, avoiding the stress associated with forced feeding and providing knowledge about the effects of voluntary ethanol consumption as observed in society (Gapp et al. 2014, Martinez et al. 2016).

This study was conducted in two experimental phases. The $1^{\text {st }}$ one utilized the retrospective analysis to verify the ethanol consumption, consumer body weight, litter size, and sex ratio of offspring from control (C) and low (L) and high (H) drinkers-ethanol groups. The data were collected throughout ten years (2005 - 2015), at Anatomy's Bioterium (IBB/UNESP). Due to significant results from 1st phase, referring to the reproductive capacity of drinkers, we additionally analysis the gestational parameters (body weight and feed and water consumption on gestation), initial development of ethanol-naïve offspring (landmarks of physical development and body weight), and maternal and paternal reproductive parameters (reproductive organs weight and sperm morphology), on $2^{\text {nd }}$ phase.

\section{$1^{\text {st }}$ experimental phase: retrospective analysis}

\section{Ethanol consumption of females and males drinkers}

The daily ethanol ingestion was determined in males and females $(n=70 / \operatorname{sex} /$ group) from low $(\mathrm{L})$ and high $(\mathrm{H})$ ethanol groups. The average ethanol consumption was obtained from PND 65-80 and measured by (ethanol consumed (ml) / $15 \times 100$ ) / body weight $(\mathrm{g})$.

\section{Body weight on postpuberty}

The average body weight of females and males from $\mathrm{C}, \mathrm{L}$ and $\mathrm{H}$ groups was compared ( $\mathrm{n}=25$ / sex / group). The animals were weighed at PND 80, period referent to end of ethanol consumption after consecutive use.

\section{Litter size and sex ratio of offspring}

The litter size and sex ratio of offspring were analyzed from C, L and H $(n=110$ couples / group). The sex ratio of offspring was verified by the count of females and males 
at birth since sex dimorphism in neonates is evidenced by the shorter distance between the anus and the genital tubercle of females (Gallavan et al. 1999). Only the first generation (F1) data were considered in this analysis. The long-term reproductive capacity was determined by the litter size from the first and second-generation (F1 and $\mathrm{F} 2, \mathrm{n}=15$ couples / generation / group).

\section{$2^{\text {nd }}$ experimental phase: parameters of parents and offspring}

\section{Dams' parameters on gestation}

In order to evaluate the evolution of pregnancy, females of $C(n=8), L(n=8)$ and $H(n=8)$ were mated to males of $C(n=8), L(n=8)$ and $H(n=8)$, respectively, at 100 days old at overnight (one female and one male / cage). Vaginal smear was carried out daily in the morning and the first day of pregnancy was considered when spermatozoa were found. After the pregnancy detection, gestational day (GD) 0 , the dams were individualized and monitored. Body weight and feed and water consumption on gestation were weekly measured.

\section{Offspring body weight and landmarks of physical development}

At birth, the offspring were cut to eight pups (four females and four males) per dam. The body weight of offspring was measured on birth from $C, L$ and $H(n=32$ sex / group) and the litter body weight ( $\mathrm{n}=8 /$ litter / group) was weekly monitored, from PND 1- 21, period that includes the neonatal (PND 0 - 7), early infantile (PND 8 - 14) and late infantile (PND 15 - 21) phases. To evaluate the initial physical development, pinna unfolding, hair growth and eye-opening were also daily observed.

\section{Parents reproductive organs weight and adiposity index}

The females ( $\mathrm{n}=8 /$ group) and males ( $\mathrm{n}=8$ / group) from control (C) and high ethanol drinker $(\mathrm{H})$ were weighted and euthanized by $\mathrm{CO}_{2}$ inhalation followed by decapitation at PND 150. Females were killed in the estrus phase. The testis, epididymis, ventral prostate, and seminal vesicle (with fluid) in the males, and ovaries and uterus in the females were removed, dissected, and weighed on analytical balance. The relative 
organs weight was calculated by organ weight $(\mathrm{mg})$ / body weight $(\mathrm{g})$. The adiposity index was also calculated by [(retroperitoneal fat + visceral fat + epididymal/ovarian fat $)$ / final body weight] $* 100$.

\section{Paternal sperm morphology}

The volume of ten microliters of semen was obtained from vas deferens of fathers from $\mathrm{C}$ and $\mathrm{H}$ group, at PND 150. Seminal fluid was placed on the slide, dried at room temperature for 10 minutes and evaluated under phase-contrast microscopy (400X, total magnification). Two hundred sperm per animal were evaluated for head or flagellar defects (Seed, et al. 1996). Anomalies were classified into head anomalies (neither typical nor isolated hook) or tail anomalies (broken or tail headless) and the data were expressed in percentage (Filler 1993).

\section{Statistical analysis}

The data were analyzed by the software GraphPad Prism ${ }^{\circledR}$ (version 7, GraphPad Software, San Diego, CA, USA). A one-way ANOVA (parametric data) was used in body weight on postpuberty and physical development of offspring. Post-hoc analysis was performed by Tukey's multiple comparison test. A Kruskal-Wallis (non-parametric data) was used in litter size and offspring sex ratio. Post-hoc analysis was performed by multiple comparison Dunn's test. A two-way ANOVA was employed in dams' parameters on gestation and offspring body weight gain. Post-hoc analysis was performed by Sidak's multiple comparison test. Time, treatment, and interaction values were expressed in the figure and table legends. Unpaired t test (parametric data) was employed in the ethanol consumption, parents' reproductive organs weight and adiposity index and paternal sperm morphology. Results were expressed as mean \pm S.D. (standard deviation) or median and interquartile range. The differences were considered significant when $\mathrm{P}<$ 0.05 .

\section{Results}




\section{Females consumed more ethanol than males}

We observed sex-specific differences related to ethanol consumption in both low $(\mathrm{P}=0.0004)$ and high $(\mathrm{P}=0.0383)$ ethanol groups. Females $(\mathrm{L}: 1.56 \pm 0.25 \mathrm{~g} / \mathrm{kg} / \mathrm{day}$; $\mathrm{H}: 4.90 \pm 1.89 \mathrm{~g} / \mathrm{kg} /$ day) ingested higher amount of ethanol than males (L: $1.27 \pm 0.34$ $\mathrm{g} / \mathrm{kg} /$ day; H: $4.27 \pm 1.53 \mathrm{~g} / \mathrm{kg} /$ day) .

\section{The long-term postpuberty ethanol use decreased body weight}

There was a lower body weight in the $\mathrm{L}$ and $\mathrm{H}$ groups, independently of sex, compared to C (Table 1).

Table 1. Comparison of females and males body weight from control (C), low (L) and high (H) ethanol groups on post-natal day 80 , period correspondent to the end of consecutive ethanol consumption between drinkers' groups ( $\mathrm{n}=30 / \mathrm{sex} /$ group).

\section{Groups}

Parameter

\begin{tabular}{lllllll}
\hline & Females & & & Males & \\
& & & & & \\
\hline C & L & H & C & L & H
\end{tabular}

Body weight

$245.1 \pm$

$196.6 \pm$

$208.9 \pm$

$394.4 \pm$

$309.0 \pm$

$305.5 \pm$

(g)

$10.5^{\mathrm{a}}$

$10.9^{\mathrm{b}}$

$28.4^{\mathrm{b}}$

$13.7^{\text {a }}$

$27.6^{\mathrm{b}}$

$42.3^{\mathrm{b}}$

Values expressed as mean \pm S.D. P values were calculated using a one-way ANOVA. ${ }^{\text {a, b }}$ Different letters represent significant differences among groups $(\mathrm{P}<0.05)$ from post-hoc Tuckey's multiple comparisons test.

The ethanol uses reduced litter size with dose-related effects, but not impacted on sex ratio of offspring

The litter size from $\mathrm{L}$ and $\mathrm{H}$ groups was lower compared to $\mathrm{C}$. We observed reduced litter size in the $\mathrm{H}$ (Figure 1A) between drinkers' groups. Thus, the greater ethanol use was the most damaging to the litter size. The comparison of litter size between 
generations is represented in Figure 1B. Only the $\mathrm{H}$ group showed reduced litter size comparing F1 to the F2.

There were no differences in the sex ratio of offspring from $\mathrm{C}, \mathrm{L}$ and $\mathrm{H}$ groups (females: $\mathrm{C}=51.38 \% \pm 15.82 ; \mathrm{L}=50.53 \% \pm 18.02 ; \mathrm{H}=50.74 \% \pm 17.30$; males: $\mathrm{C}=$ $48.62 \% \pm 15.53 ; \mathrm{L}=49.47 \% \pm 18.02 ; \mathrm{H}=49.26 \% \pm 17.00)$.

A

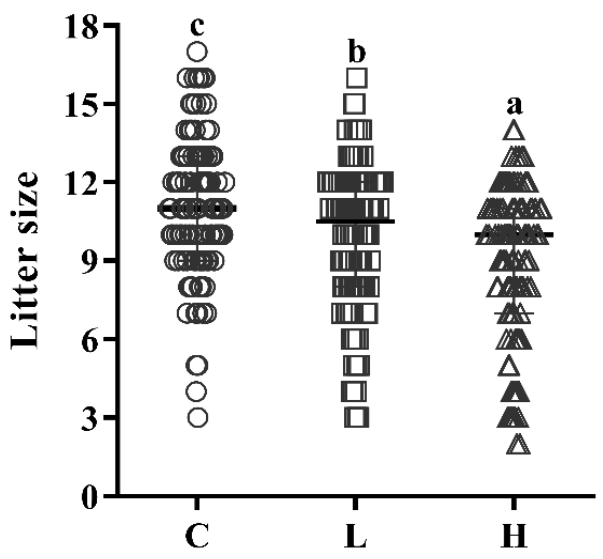

Groups
B

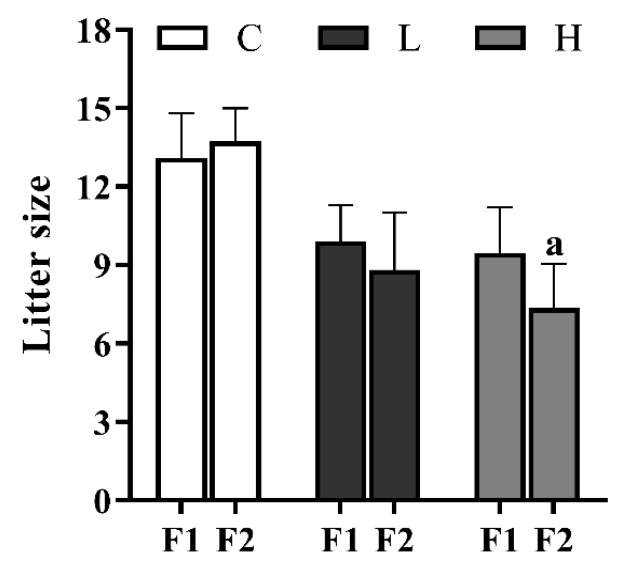

Generation

Figure 1. Comparison of litter size from control (C), low drinker (L), and high drinker (H) groups. A) Litter size from $C(n=110), L(n=110)$ and $H(n=110)$ groups. Values expressed as median and interquartile range. $\mathrm{P}$ values were calculated using a Kruskal-Wallis test. ${ }^{\mathrm{a}, \mathrm{b}, \mathrm{c}}$ Different letters represent significant differences among groups $(\mathrm{P}<0.05)$ from post hoc Dunn's multiple comparisons test. B) Litter size of first (F1) and second (F2) generation from $\mathrm{C}(\mathrm{n}=15), \mathrm{L}(\mathrm{n}=15)$ and $\mathrm{H}(\mathrm{n}=15)$ groups. Values expressed as mean \pm S.D. $\mathrm{P}$ values were calculated using a two-way ANOVA. ${ }^{\text {a }}$ Significant difference between generations $(\mathrm{P}<0.05)$ from post-hoc Sidak's multiple comparison test. Figure 1B: $\mathrm{P}_{\text {Inter }}=0.0595, \mathrm{P}_{\text {Time }}=$ $0.0709, \mathrm{P}_{\text {Treat }}<0.0001$.

\section{$2^{\text {nd }}$ experimental phase: parameters of parents and offspring}

The low and high ethanol use decreased gestational body weight gain and feed consumption, no dose-related effects

The maternal body weight on GD 0 and GD 21 was lower in both postpubertal ethanol exposed groups compared to control (GD0 C: $285.4 \pm 14.9$, L: $236.7 \pm 11.5$, H: 
$246.4 \pm 11.8 ;$ GD $21 \mathrm{C}: 315.0 \pm 34.7, \mathrm{~L}: 286.7 \pm 12.7, \mathrm{H}: 287.2 \pm 7.8)$. However, the dams body weight gain from $\mathrm{L}$ and $\mathrm{H}$ groups was lower only on the $3^{\text {rd }}$ gestational week (Figure 2C). Regarding the feed and water consumption, we observed lower consumption in the $\mathrm{L}$ and $\mathrm{H}$ dams on the $2^{\text {nd }}$ and $3^{\text {rd }}$ gestational weeks, respectively (Figures $2 \mathrm{~A}-\mathrm{B}$ ).

A

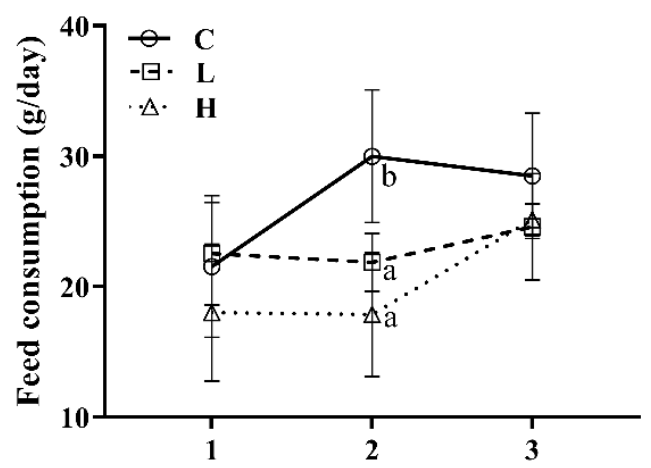

C

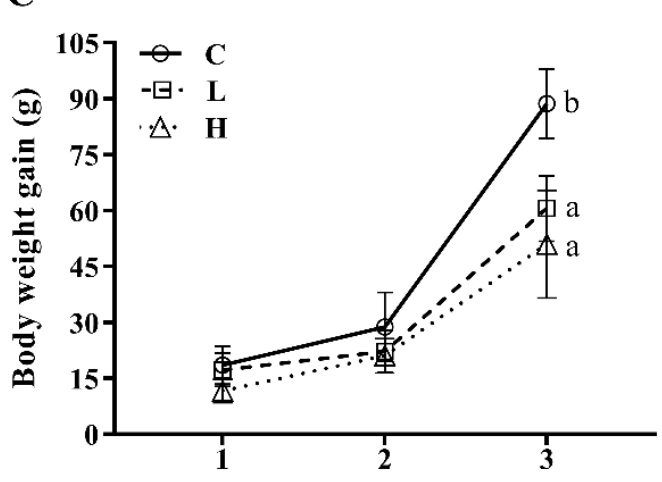

Gestational week
B

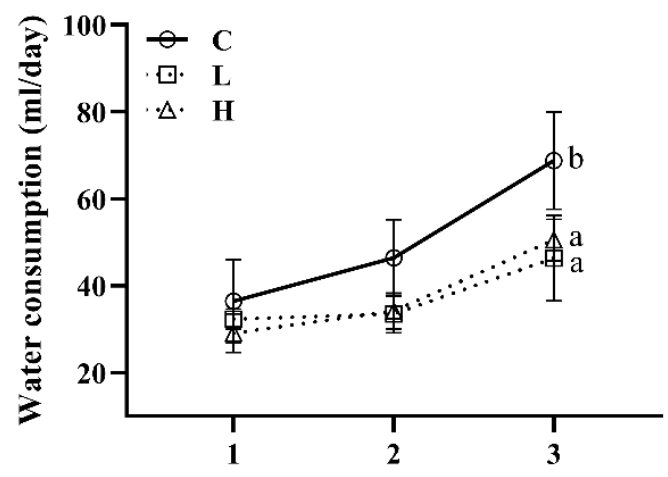

Gestational week

Figure 2. Dams' parameters on gestation of control (C), low drinker $(\mathrm{L})$ and high drinker $(\mathrm{H})$. A) Feed consumption, B) Water consumption, C) Body weight gain of $\mathrm{C}(\mathrm{n}=8), \mathrm{L}(\mathrm{n}=8)$ and $\mathrm{H}(\mathrm{n}=8)$. Values expressed as mean \pm S.D. P values were calculated using a two-way ANOVA. ${ }^{a, b}$ Different letters represent significant differences among groups $(\mathrm{p}<0.05)$ from post-hoc Sidak's multiple comparison test. Figures $2 \mathrm{~A}: \mathrm{P}_{\text {Inter }}=0.0122, \mathrm{P}_{\text {Time }}<0.0008, \mathrm{P}_{\text {Treat }}<0.0001 ; 2 \mathrm{~B}: \mathrm{P}_{\text {Inter }}=0.0701, \mathrm{P}_{\text {Time }}<0.0001, \mathrm{P}_{\text {Treat }}<0.0001 ; 2 \mathrm{C}$ : $\mathrm{P}_{\text {Inter }}<0.0001, \mathrm{P}_{\text {Time }}<0.0001, \mathrm{P}_{\text {Treat }}<0.0001$.

Low and high postpubertal parental ethanol use impaired body weight and physical development of ethanol-naive offspring, with dose-related effects 
Figure 3 represents the parameters of female and male offspring from C, L, and $\mathrm{H}$ groups. The pups sired by low and high postpubertal parental ethanol use had a lower body weight at birth and throughout the infant period (PND 1 -21) compared to control (Figure $3 \mathrm{~A}$ ). The damages on the offspring were correlated to the amount of ethanol consumed by parents since the offspring from high drinkers' group showed lower body weight compared to offspring from low drinkers' group.

A

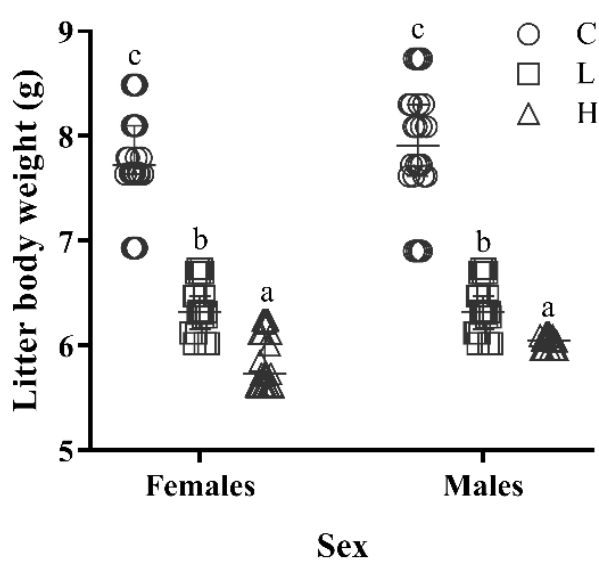

B

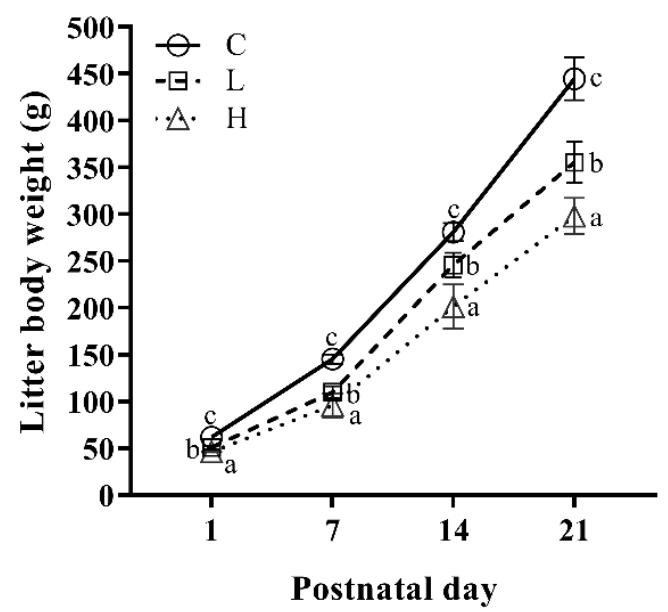

Figure 3. Parameters of female and male offspring from control (C), low drinker $(\mathrm{L})$ and high drinker $(\mathrm{H})$ groups. A) Body weight on birth of females and males ( $n=32$ / sex / group). Values expressed as median and interquartile range. $P$ values were calculated using a Kruskal-Wallis test. ${ }^{\mathrm{a}, \mathrm{b}, \mathrm{c}}$ Different letters represent significant differences among groups $(\mathrm{P}<0.05)$ from post hoc Dunn's multiple comparisons test. $\mathrm{B})$ Litter body weight (females and males) on postnatal day 1 to 21 ( $\mathrm{n}=8$ /litter/ group). Values expressed as mean \pm S.D. P values were calculated using a two-way ANOVA. ${ }^{\text {a }, ~ b, ~ c ~ D i f f e r e n t ~ l e t t e r s ~ r e p r e s e n t ~ s i g n i f i c a n t ~}$ differences among groups $(\mathrm{P}<0.05)$ from post-hoc Sidak's multiple comparison test. Figure 3B: $\mathrm{P}_{\text {Inter }}<$ $0.0001, \mathrm{P}_{\text {Time }}<0.0001, \mathrm{P}_{\text {Treat }}<0.0001$.

The landmarks of physical development were changed on the offspring from low and high drinkers' groups. It was observed earlier eye-opening in the offspring from $\mathrm{L}$ and delayed hair growth in the $\mathrm{H}$ (Table 2). 
Table 2. Comparison of the mean day of physical development landmarks in days in the offspring $(\mathrm{n}=8 /$ litter / group) from control (C), low drinker (L) and high drinker (H) groups.

\begin{tabular}{cccc}
\hline Parameters & \multicolumn{3}{c}{ Groups } \\
\cline { 2 - 4 } (days) & $\mathbf{C}$ & $\mathbf{L}$ & $\mathbf{H}$ \\
\hline Pinna unfolding & $2.5 \pm 0.5$ & $2.3 \pm 0.8$ & $3.1 \pm 0.8$ \\
Hair growth & $4.7 \pm 0.4^{\mathrm{a}}$ & $4.8 \pm 0.5^{\mathrm{a}}$ & $5.7 \pm 0.4^{\mathrm{b}}$ \\
Eye-opening & $14.2 \pm 0.3^{\mathrm{b}}$ & $13.6 \pm 0.3^{\mathrm{a}}$ & $14.3 \pm 0.5^{\mathrm{b}}$
\end{tabular}

Values expressed as mean \pm S.D. P values were calculated using a one-way ANOVA. ${ }^{\text {a, b }}$ Different letters represent significant differences among groups $(\mathrm{P}<0.05)$ from post-hoc Tukey's multiple comparison test.

High postpubertal ethanol use decreased female and male reproductive organs weight on adulthood and impaired paternal sperm morphology

We did not get data from the parental reproductive organs and the paternal sperm morphology of the low drinker group. Therefore, in this analysis only data from control and high drinkers' groups were compared.

There was lower uterine weight and adiposity index in the females from $\mathrm{H}$ group, but the body weight did not alter. On the other hand, the body weight was lower and sex glands (epididymis and seminal vesicle) was greater in the males from $\mathrm{H}$ (Table 3).

Table 3. Comparison of body weight, relative reproductive organs weight and adiposity index at post-natal day 150 in the females and males from control (C) and high drinkers $(\mathrm{H})$ groups $(\mathrm{n}=8$ / sex / group).

\begin{tabular}{llll}
\hline \multirow{2}{*}{ Parameters } & \multicolumn{2}{c}{ Groups } \\
& & C & H \\
\cline { 2 - 4 } & & & \\
\hline
\end{tabular}

\section{Females}

$\begin{array}{lcc}\text { Body weight }(\mathrm{g}) & 315.01 \pm 30.99 & 287.2 \pm 8.77 \\ \text { Ovaries }(\mathrm{mg} / \mathrm{g}) & 0.46 \pm 0.04 & 0.43 \pm 0.02 \\ \text { Uterus }(\mathrm{mg} / \mathrm{g}) & 2.13 \pm 0.12 & 1.62 \pm 0.15^{*} \\ \text { Adiposity index } & 3.99 \pm 0.73 & 3.00 \pm 0.31^{*}\end{array}$




\section{Males}

$\begin{array}{lcc}\text { Body weight }(\mathrm{g}) & 506.05 \pm 12.22 & 408.00 \pm 16.37^{*} \\ \text { Testis }(\mathrm{mg} / \mathrm{g}) & 3.67 \pm 0.29 & 4.02 \pm 0.29 \\ \text { Epididymis }(\mathrm{mg} / \mathrm{g}) & 1.50 \pm 0.09 & 1.72 \pm 0.02^{*} \\ \text { Ventral prostate }(\mathrm{mg} / \mathrm{g}) & 3.08 \pm 0.22 & 3.28 \pm 0.67 \\ \text { Seminal vesicle }(\mathrm{mg} / \mathrm{g}) & 3.95 \pm 0.95 & 5.62 \pm 0.77^{*} \\ \text { Adiposity index } & 2.93 \pm 0.62 & 2.85 \pm 0.46\end{array}$

Values expressed as mean \pm S.D. P values were calculated using a t test. ${ }^{*}$ Significant difference between groups $(\mathrm{P}<0.05)$.

Regarding paternal sperm morphology, there was an increase in the percentage of sperm with morphologic abnormalities in the early high exposed to ethanol group, including a higher incidence of head and tail defects (Table 5).

Table 5. Paternal sperm morphology on post-natal day 150 in the males from control $(\mathrm{C})$ and high drinkers (H) groups ( $\mathrm{n}=8 /$ group).

\begin{tabular}{lcc}
\hline \multirow{2}{*}{ Parameters $(\%)$} & \multicolumn{2}{c}{ Groups } \\
\cline { 2 - 3 } & \multicolumn{2}{c}{ C } \\
\hline Normal sperm & $91.25(90.38-92.63)$ & $75(70.38-81.25)^{*}$ \\
Abnormal sperm & $8.75(7.37-9.62)$ & $25(18.75-29.63)^{*}$ \\
Broken tail & $0.56(0.50-0.71)$ & $0.75(0.00-3.00)$ \\
Headless & $1.56(0.87-2.09)$ & $4.00(2.87-4.12)^{*}$ \\
Isolated head & $5.87(4.50-6.87)$ & $19.75(12.50-23.75)^{*}$
\end{tabular}

Values expressed as median and interquartile range (IQ1 - IQ3). P values were calculated using a t test. Significant difference between groups $(\mathrm{P}<0.05)$. 


\section{Discussion}

This is the first study to conduct a retrospective analysis of postpubertal ethanol use and its effects on the reproduction in the voluntary model of low and high ethanol consumption. Our results highlight how lifestyle after adolescence modulates long-term reproductive parameters and future generations. The low and high postpuberty ethanol use impairs reproduction, even after withdrawal, and the development of ethanol-naive offspring, being high alcohol drinking the most harmful.

Ethanol consumption is historically higher in men, however, the difference between sexes has been disappearing (Becker \& Koob 2016). We observed greater ethanol ingestion in females from both drinking groups. These findings can be partially attributed to biological differences established by hormonal status during development since estrogen receptors are found in structures belonging to mesocorticolimbic reward pathways and in serotoninergic function (Bethea et al. 2002, Witt 2007, Becker \& Koob 2016). Ethanol is a caloric substance and could interfere in regular nutrition (Gruchow et al. 1985), thus, we observed lower body weight in females and males $\mathrm{L}$ and $\mathrm{H}$ after 15 consecutive days of exposure. Increased energy expenditure and lipid oxidation and poor nutritional status due to a decrease in non-alcoholic calorie intake may be related (Addolorato et al. 1998, Ojeda et al. 2009, Sebastiani et al. 2018).

In this perspective, postpubertal alcohol use also led to lower weight gain and feed consumption on gestation in the $\mathrm{L}$ and $\mathrm{H}$ dams, with dose-related effects. Increased plasma leptin during abstinence (Kiefer et al. 2005) contributes to decreased food intake. On the other hand, the inefficiency in the absorption of ingested calories can also act, since the metabolism of ethanol changes the intestinal permeability and harms the organic systems function (Bishehsari et al. 2017). In addition, the lower weight gain could be associated with the weight of the pregnant uterus (Kind et al. 2006), fetal and placental (Brett et al. 2014), as we found lower litter size and body weight at birth of the offspring from $\mathrm{L}$ and $\mathrm{H}$ groups.

Considering the direct-ethanol toxicity, gestational exposure can reduce litter size, especially in the high drinkers (Cicero et al. 1994, Ojeda et al. 2009, Li et al. 2012). Interestingly, we found that postpubertal ethanol use also decreased litter size but did not alter offspring sex ratio. Impacts on blastocyst implantation, oxidative damage to germline DNA compromising the embryo cells, abnormal fetal development, and 
increased rates of resorption and abortion may be mechanisms contributing to these results (Cicero et al. 1994, Ward et al. 1996, Emanuele et al. 2001, Jana et al. 2010, Jensen et al. 2014). We hypothesize the reproductive capacity of high drinkers was chronically affected, as there was a decreased litter size between the first- and- second-generation.

The reproductive organs' weight has been used to evaluate the toxicity of the reproductive system (Clegg et al. 2001). We found alterations in the female and male reproductive organs in the high drinkers' group. Studies noticed an irregularity in the estrous cycle, reduction of $\mathrm{LH}$ and $\mathrm{FSH}$, follicular atresia, and damage in uterine endometrial cells in drinkers, with effects related to the dose consumed (Chuffa et al. 2009, Martinez et al. 2016). Acetaldehyde and oxidative stress increase and impairs to HPG/HPA axes are mechanisms that change reproductive hormones balance and, consequently, uterine and ovarian tissues (Buthet et al. 2003, Rachdaoui \& Sarkar 2017). We suggest that lower uterine weight in $\mathrm{H}$ females could be related to a hormonal imbalance with damage to uterine structure and function. The lower adiposity index observed in females from the $\mathrm{H}$ group could also highlight possible malnutrition due to loss of muscle or fat mass (Dasarathy 2016). Relating to males, studies have evaluated alcohol exerting a direct effect on both testosterone metabolism and spermatogenesis (Sansone et al. 2018). In contrast to the literature that reports atrophy of reproductive organs in drinkers (Martinez et al. 2000; 2001), we found an increase in the epididymis and seminal vesicle weight. Alcohol consumption can affect the autonomic nervous system, with sacral denervation leading to erectile dysfunction (Johnson et al. 1986, Julian et al. 2019). Changes in contractility and innervation of these organs increase epididymis sperm reserve and drive to accumulation or retention of fluid in the seminal vesicle (Fernandez et al. 2008). Furthermore, we found an increased percentage of sperm with morphological abnormalities similar to clinical (Pajarinen et al. 1996, La Vignera et al. 2012, Sansone et al. 2018) and experimental (Jana et al. 2010) studies. These increased abnormalities can be either due to failures in the spermatogenic process or in sperm maturation. Inadequate signalization of epididymal factors which plays a role in maturation or low testosterone levels can drive these abnormalities (Koch et al. 2015, Zi et al. 2015). The abnormal testosterone/estradiol ratio has been also associated with decreased semen parameters as well as harm on accessory sex glands (Ramasamy et al. 2016). The lower body weight of $H$ males validates the compromised growth. This parameter can indicate estrogen imbalance, as body weight has been used to measure 
estrogen potency (Heywood \& Wadsworth 1980, Hart 1990). The damage to reproductive organs and testosterone can be observed even after alcoholic withdrawal (Candido et al. 2007), then, we hypothesized toxicity to the HPG/HPA axes, leading to inadequate functioning of accessory sex glands, hormonal imbalance, and reduced sperm quality. Although additional analysis is needed to validate the real harm of ethanol on reproduction, our data indicate that high post-pubertal alcohol use can highly impair longterm reproductive function. Low doses are also harmful, nevertheless, their impacts are lesser than the high doses (Patra et al. 2011; Rahimipour et al. 2012).

Studies highlight preconception ethanol exposure can influence the descendants' phenotype. In this way, we observed that in addition to the impairment on the gestational parameters of dams early exposed to the low and high ethanol, the offspring also showed reduced body weight, with dose-related effects. Reducing the gestational sac weight, placental efficiency, and function due to maternal and paternal ethanol use (Chang et al. 2017, Gardebjer et al. 2014) could explain partially our results. Preconception nutrition, body weight index, gestational weight gain and food consumption also influence maternal metabolic response in pregnant and fetal outcomes (Kind et al. 2006, Brett et al. 2014). Associated, the paternal experiences play an additional role (Robertson 2005, Rando \& Simmons 2015) since the seminal fluid stimulates the female reproductive tract to produce growth factors and cytokines which protect the embryo (Robertson 2005) and changes in the seminal signalization are capable of influencing descendants (Bromfield et al. 2014). The landmarks of physical development on offspring sired by alcoholic use by parents were altered in our study, similar to results by Fioravante et al. (2021). The insulin-like growth factor (IGF) is important for fetal and postnatal development and IGF deficiency implicates signaling pathways and normal body growth (Kanaka-Gantenbein et al. 2003). Similarly, the endothelial growth factor (EGF) plays a role in regulating the activity of epidermal and epithelial tissues as eye-opening and hair growth (Smart et al. 1989, Calamandrei \& Alleva 1989). The alterations in the postnatal development of offspring can be also associated with maternal care (Amorim et al., 2011) since alcohol withdrawal accentuates depressive behaviors and reduced time spent on nursing (Pang et al. 201, Workman et al. 2015). We hypothesized a possible endocrine and metabolic programming of the offspring, with the parental ethanol dose as decisive in the course of this programming. 
In summary, the results presented here suggest the potentially alarming possibility in which exposure to alcohol on post puberty produces long-term effects, even in withdrawal of alcohol. The ethanol use decreased body weight, gestational feed intake, and litter size. In addition, postpuberty alcohol use increased the percentage of morphologically abnormal sperm and alternated female and male reproductive organs weight. Besides the impairments on consumers, the offspring development and growth were also affected, however, we cannot distinguish which parent contributed the most to observed changes. However, our previous laboratory studies along with published data about preconception maternal ethanol exposure strongly suggest a maternal influence as the main. The parameters evaluated show a dose-effect relationship.

Despite the limitations of this study, we highly believe that the post-adolescent period also acts as a susceptibility window. Future studies are needed to identify the longterm effects of consumption on drinkers' reproduction even in withdrawal as well as to understand the mechanisms responsible for ethanol-naive offspring outcomes. Possibly, the effects are associated with epigenetic germline modifications, metabolism activity and HPG/HPA axis.

\section{Funding}

This study was financed by the Grant 2018/12354-5, São Paulo Research Foundation (FAPESP), and Coordination for the Improvement of Higher Education Personnel - Brazil (CAPES) - Finance Code 001.

\section{References}

Addolorato, G., Capristo, E., Greco, A.V., Stefanini, G.F., \& Gasbarrini, G. (1998). Influence of chronic alcohol abuse on body weight and energy metabolism: is excess ethanol consumption a risk factor for obesity or malnutrition? Journal of Internal Medicine 244 387-395. (https://doi. org/10.1046/j.13652796.1998.00381.x)

Anderson, R. A., Beyler, B.S., \& Zaneveld, L. J. D. (1978). Alterations of male reproduction induced by chronic ingestion of ethanol: development of an animal model. Fertility and sterility, 30, $103-105$. (https://doi: 10.1016/s0015-0282(16)43406-0) 
Amorim, J. P., Chuffa, L. G., Teixeira, G. R., Mendes, L. O., Fioruci, B. A., Martins, A., \& Martinez, F. E. (2011) Variations in maternal care alter corticosterone and 17beta-estradiol levels, estrous cycle and folliculogenesis and stimulate the expression of estrogen receptors alpha and beta in the ovaries of UCh rats. Reproductive Biology and Endocrinology, 9, 1-12. (https://dx.doi.org/10.1186/1477-7827-9-160)

Asimes, A., Kim, C. K., Cuarenta, A., Auger, A. P., \& Pak, T. R. (2018). Binge drinking and intergenerational implications: parental preconception alcohol impacts offspring development in rats. Journal of the Endocrine Society, 2, 672-686. (https://doi.org/10.1210/js.2018-00051)

Asimes, A., Torcaso, A., Pinceti, E., Kim, C. K., Zeleznik-le, N. J., \& Pak, T. R. (2017). Adolescent bingepattern alcohol exposure alters genome-wide DNA methylation patterns in the hypothalamus of alcoholnaïve male offspring. Alcohol, 60, 179-189. (https://doi.org/10.1016/j.alcohol.2016.10.010)

Balddin, J., Berglund, K. J., Berggren, U., Wennberg, P., \& Fahlke, C. (2018). TAQ1A1 Allele of the DRD2 gene region contribute to shorter survival time in alcohol dependent individuals when controlling for the influence of age and gender: a follow-up study of 18 years. Alcohol and Alcoholism, 53, 216-220. (https://doi.org/10.1093/alcalc/agx089)

Barazani, Y., Katz, B. F., Nagler, H. M., \& Stember, D. S. (2014). Lifestyle, environment, and male reproductive health. The Urologic clinics of North America, 41, 55-66. (https://doi:10.1016/j.ucl.2013.08.017)

Becker, J., \& Koob, G. (2016). Sex differences in animal models: focus on addiction. Pharmacological Research, 68, 242-263. (https://DOI: 10.1124/pr.115.011163)

Bethea, C. L., Lu, N. Z., Gundlah, C., \& Streicher, J. M. (2002). Diverse Actions of Ovarian Steroids in the Serotonin Neural System. Frontiers in Neuroendocrinology, 23, 41-100. doi:10.1006/frne.2001.0225 (https://doi.org/10.1006/frne.2001.0225)

Bishehsari, F., Magno, E., Swanson, G., Desai, V., Voigt, R. M., Forsyth, C. B., \& Keshavarzian, A. (2017). Alcohol and Gut-Derived Inflammation. Alcohol research: current reviews, 38, 163-171.

Brett, K.E., Ferraro, Z.M., Yockell-Lelievre, J., Gruslin, A., \& Adamo, K.B. (2014). Maternal-fetal nutrient transport in pregnancy pathologies: the role of the placenta. International Journal of Molecular Sciences, 15, 16153-16185. (https://doi.org/10.3390/ijms150916153)

Bromfield, J. J., Schjenken, J. E., Chin, P. Y., Care, A. S., Jasper, M. J., \& Robertson, S. A. (2014). Maternal tract factors contribute to paternal seminal fluid impact on metabolic phenotype in offspring. Proceedings of the National Academy of Sciences, 111, 2200-2205. (https://doi:10.1073/pnas.1305609111)

Buthet, L. R., Maciel, M. E., Quintans, L. N., Rodríguez de Castro, C., Costantini, M. H., Fanelli, S. L., et al. (2013). Acetaldehyde content and oxidative stress in the deleterious effects of alcohol drinking on rat uterine horn. Journal of Toxicology, 1-12. (https://dx.doi.org/10.1155/2013/161496). 
Calamandrei, G., \& Alleva, E. (1989). Epidermal growth factor has both growth-promoting and growthinhibiting effects on physical and neurobehavioral development of neonatal mice. Brain Research, 477, 16. (https://doi:10.1016/0006-8993(89)91387-5)

Candido, E., Carvalho, C., Martinez, F., \& Cagnon, V. (2007). Experimental alcoholism and pathogenesis of prostatic diseases in UChB rats. Cell Biology International, 31, 459-472. (https://doi:10.1016/j.cellbi.2006.11.009)

Chang, R.C., Skiles, W.M., Chronister, S.S., Wang, H., Sutton, G.I., Bedi, Y.S., Snyder, M., Long, C.R., \& Golding, M.C. (2017). DNA methylation-independent growth restriction and altered developmental programming in a mouse model of preconception male alcohol exposure. Epigenetics, 12, 841-853. (https://doi.org/10.1080/15592294.2017.1363952)

Chuffa, L.G.A., Padovani, C.R., \& Martinez, F.E. (2009). Ovarian structure and hormonal status of the UChA and UChB adult rats in response to ethanol. Maturitas, 62, 21-29. (https://doi:10.1016/j.maturitas.2008.09.027)

Cicero, T. J., Lynno' Connor, B. N., Adams, M. L., Sewing, B. N., \& Meyer, R. (1994). Acute alcohol exposure markedly influences male fertility and fetal outcome in the male rat. Life Sciences, 55, 901-910. (https://doi:10.1016/0024-3205(94)00535-4)

Clegg, E. D., Perreault, D. \& Klinefelter, G. R. (2001) Assessment of male reproductive toxicity. In: Principles and Methods of Toxicology (ed. A. W. Hayes), pp. 1263-1300. Taylor \& Francis, Philadelphia, PA.

Dasarathy, S. (2016). Nutrition and Alcoholic Liver Disease. Clinics in Liver Disease, 20(3), 535-550. (https://doi: 10.1016/j.cld.2016.02.010).

Eggert, J., Theobald, H., \& Engfeldt, P. (2004). Effects of alcohol consumption on female fertility during an 18-year period. Fertility and Sterility, 81, 379-383. (https://doi.org/10.1016/j.fertnstert.2003.06.018)

Emanuele, N.V., Lapagli, N., Steiner, J., Colantoni, A., Van Thiel, D.H., \& Emanuele, M.A. (2001). Peripubertal paternal EtOH exposure. Endocrine, 14, 213-219. (https://doi.org/10.1385/endo:14:2:213)

Fernandez, C. D. B., Porto, E. M., Arena, A. C., \& Kempinas, W. D. G. (2008). Effects of altered epididymal sperm transit time on sperm quality. International Journal of Andrology, 31, 427-437. (https://doi:10.1111/j.1365-2605.2007.00788.x)

Fioravante, V.C., Godoi, A.R., Camargo, V.M.B., Nascimento, R.S., Pinheiro, P.F.F., \& Martinez, F.E. (2021). Parents ethanol use impairs ethanol-naive offspring development and reproduction. Reproduction,161, 195-204. (https://doi: 10.1530/REP-20-0316)

Filler, R. (1993). Methods for evaluation of rats epididymal sperm morphology. In Methods in Toxycology: Male Reproductive Toxicology, pp. 334-343. Eds RE Chapin \& JH Heindel. San Diego: Academic Press. 
Gallavan, R. H., Holson, J. F., Stump, D. G., Knapp, J. F., \& Reynolds, V. L. (1999). Interpreting the toxicologic significance of alterations in anogenital distance: potential for confounding effects of progeny body weights. Reproductive Toxicology, 13, 383-390. (https://doi.org/10.1016/s0890- 6238(99)00036-2)

Gardebjer, E. M., Cuffee, J. S. M., Pantaleon, M., Wlodek, M. E., \& Moritz, K. M. (2014) Periconceptional alcohol consumption causes fetal growth restriction and increases glycogen accumulation in the late gestation rat placenta. Placenta, 35, 50-57. (https://doi.org/10.1016/j.placenta.2013.10.008)

Gapp, K., Jawaid, A., Sarkies, P., Bohacek, J., Pelczar, P., Prados, J., Farinelli, L., Miska, E., \& Mansuy, I. M. (2014). Implication of sperm RNAs in transgenerational inheritance of the effects of early trauma in mice. Nature Neuroscience, 17, 667-669. (https://doi.org/10.1038/nn.3695)

Ghazali, R., \& Patel, V. B. (2016). Alcohol Metabolism: General Aspects. Molecular Aspects of Alcohol and Nutrition, 17-21. doi:10.1016/b978-0-12-800773-0.00002-1

Global Burden of Diseases (GBD) Alcohol Collaborators. (2018). Alcohol use and burden for 195 countries and territories, 1990-2016: a systematic analysis for the Global Burden of Disease Study 2016. The Lancet, 392, 1015-1035.

Gruchow, H. W., Sobocinski, K. A., Barboriak, J. J., \& Scheller, J. G. (1985). Alcohol consumption, nutrient intake and relative body weight among US adults. The American Journal of Clinical Nutrition, 42, 289-295. (https://doi:10.1093/ajcn/42.2.289)

Harding, S. M., Mollé, N., Reyes-Fondeur, L., \& Karanian, J. M. (2016). The Effects of Repeated Forced Ethanol Consumption During Adolescence on Reproductive Behaviors in Male Rats. Alcohol, 55, 61-68. (https://doi.org/10.1016/j.alcohol.2016.08.004)

Hart, J. E. (1990). Endocrine pathology of estrogens: Species differences. Pharmacology \& Therapeutics, 47, 203-218. (https://doi:10.1016/0163-7258(90)90087-i)

Heywood, R., \& Wadsworth, P. F. (1980). The experimental toxicology of estrogens. Pharmacology \& Therapeutics, 8, 125-142. (https://doi:10.1016/0163-7258(80)90062-5)

Jana, K., Jana, N., Kumar, D.K., \& Guha, S.K. (2010). Ethanol induces mouse spermatogenic cell apoptosis in vivo through over-expression of fas/fas-1, p53, and caspase-3 along with cytochrome c translocation and glutathione depletion. Molecular Reproduction and Development, 77, 820-833. (https://doi.org/10.1002/mrd.21227)

Jensen, T. K., Gottschau, M., Madsen, J. O. B., Andersson, A.-M., Lassen, T. H., Skakkebaek, N. E., \& Jorgensen, N. (2014). Habitual alcohol consumption associated with reduced semen quality and changes in reproductive hormones; a cross-sectional study among 1221 young Danish men. BMJ Open, 4, 5462-5462. (https://doi:10.1136/bmjopen-2014-005462)

Johnson, R. H., Eisenhofer, G., \& Lambie, D. G. (1986). The effects of acute and chronic ingestion of ethanol on the autonomic nervous system. Drug and Alcohol Dependence, 18, 319-328. (https://doi:10.1016/0376-8716(86)90094-3) 
Julian, T. H., Syeed, R., Glascow, N., \& Zis, P. (2019). Alcohol-induced autonomic dysfunction: a systematic review, 20, 29-41. Clinical Autonomic Research. (https:/doi:10.1007/s10286-019-00618-8)

Kanaka-Gantenbein, C., Mastorakos, G., \& Chrousos, G. P. (2003). Endocrine-Related Causes and Consequences of Intrauterine Growth Retardation. Annals of the New York Academy of Sciences, 997, 150-157. (https://doi:10.1196/annals.1290.017)

Kiefer, F., Jahn, H., Otte, C., Demiralay, C., Wolf, K., \& Wiedemann, K. (2005). Increasing leptin precedes craving and relapse during pharmacological abstinence maintenance treatment of alcoholism. Journal of Psychiatric Research, 39, 545-551. (https://doi.org/10.1016/j.jpsychires.2004.11.005)

Kind, K.L., Moore, V.M., \& Davies, M.J. (2006). Diet around conception and during pregnancy-effects on fetal and neonatal outcomes. Reproductive Biomedicine Online, 12, 532-541. (https://doi.org/10.1016/s1472-6483(10)61178-9)

Koch, S., Acebron, S. P., Herbst, J., Hatiboglu, G., \& Niehrs, C. (2015). Post-transcriptional Wnt Signaling Governs Epididymal Sperm Maturation. Cell, 163, 1225-1236. (https://doi:10.1016/j.cell.2015.10.029)

La Vignera, S., Condorelli, R. A., Balercia, G., Vicari, E., \& Calogero, A. E. (2012). Does alcohol have any effect on male reproductive function? A review of literature. Asian Journal of Andrology, 15, 221-225. (https://doi:10.1038/aja.2012.118)

Liang, F., Diao, L., Liu, J., Jiang, N., Zhang, J., Wang, H., \& Ma, D. (2014). Paternal ethanol exposure and behavioral abnormities in offspring: Associated alterations in imprinted gene methylation. Neuropharmacology, 81, 126- 133. (https://doi:10.1016/j.neuropharm.2014.01.025)

Li, N., Fu, S., Zhu, F., Deng, X., \& Shi, X. (2012). Alcohol intake induces diminished ovarian reserve in childbearing age women. Journal of Obstetrics and Gynaecology Research, 39, 516-521. (https://doi:10.1111/j.1447-0756.2012.01992.x

Mardones, J., \& Segovia-Riquelmi, N. (1983). Thirty-two years of rats by ethanol preference: UChA and UChB strains. Neurobehavioral Toxicology and Teratology, 5, 171-178.

Martinez, M., Milton, F. A., Pinheiro, P. F. F., Almeida-Francia, C. C. D., Cagnon-Quitete, V. H. A., Tirapelli, L. F., \& Martinez, F. E. (2016). Chronic ethanol intake leads to structural and molecular alterations in the rat endometrium. Alcohol, 52, 55-61. (https://doi:10.1016/j.alcohol.2016.02.002)

Martinez, F.E., Martinez, M., Padovani, C.R., Bustos-Obregón, E. (2000). Morphology of testis and epididymis in an ethanol-drinking rat strain (UChA and UChB), Journal of Submicroscopic Cytology and Pathology, 32,175-84.

Martinez, F.E., Laura, I.A., Martinez, M., Padovani, C.R., Bustos-Obregón, E. (2001). Morphology of the ventral lobe of the prostate and seminal vesicles in an ethanol-drinking strain of rats (UChA and UChB). Journal of Submicroscopic Cytology and Pathology, 33, 99-106. 
Oremosu, A. A., \& Akang, E. N. (2015). Impact of alcohol on male reproductive hormones, oxidative stress and semen parameters in Sprague-Dawley rats. Middle East Fertility Society Journal, 20, 114-118. (https://doi. org/10.1016/j.mefs.2014.07.001)

Ojeda, M. L., Vázquez, B., Nogales, F., Murillo, M. L., \& Carreras, O. (2009). Ethanol Consumption by Wistar Rat Dams Affects Selenium Bioavailability and Antioxidant Balance in Their Progeny. International Journal of Environmental Research and Public Health, 6, 2139-2149. (https://doi:10.3390/ijerph6082139)

Pajarinen, J., Karhunen, P. J., Savolainen, V., Lalu, K., Penttila, A., \& Laippala, P. (1996). Moderate Alcohol Consumption and Disorders of Human Spermatogenesis. Alcoholism: Clinical and Experimental Research, 20, 332-337. (https://doi:10.1111/j.1530-0277.1996.tb01648.x)

Pang, T. Y., Renoir, T., Du, X., Lawrence, A. J., \& Hannan, A. J. (2013). Depression-related behaviours displayed by female C57BL/6J mice during abstinence from chronic ethanol consumption are rescued by wheel-running. European Journal of Neuroscience, 37, 1803-1810. (htpps://doi:10.1111/ejn.12195)

Patra, J., Bakker, R., Irving, H., Jaddoe, V., Malini, S., \& Rehm, J. (2011). Dose-response relationship between alcohol consumption before and during pregnancy and the risks of low birthweight, preterm birth and small for gestational age (SGA)-a systematic review and meta-analyses. BJOG: An International Journal of Obstetrics \& Gynaecology, 118, 1411-1421. (https://doi:10.1111/j.1471-0528.2011.03050.x)

Picut, C. A., Dixon, D., Simons, M. L., Stump, D. G., Parker, G. A., \& Remick, A. K. (2015). Postnatal ovary development in the rat: morphologic study and correlation of morphology to neuroendocrine parameters. Toxicologic Pathology, 43, 343-353. (https://doi.org/10.1177/0192623314544380)

Rachdaoui, N., \& Sarkar, D.K. (2017). Pathophysiology of the Effects of Alcohol Abuse on the Endocrine System. Alcohol Research, 38, 255-276.

Rahimipour, M., Talebi, A. R., Anvari, M., Sarcheshmeh, A. A., \& Omidi, M. (2013). Effects of different doses of ethanol on sperm parameters, chromatin structure and apoptosis in adult mice. European Journal of Obstetrics \& Gynecology and Reproductive Biology, 170, 423-428. (https://doi:10.1016/j.ejogrb.2013.06.038)

Ramasamy, R., Schulster, M., \& Bernie, A. (2016). The role of estradiol in male reproductive function. Asian Journal of Andrology, 18, 435. (https://doi:10.4103/1008-682x.173932)

Rando, O. J., \& Simmons, R. A. (2015). I'm Eating for Two: Parental Dietary Effects on Offspring Metabolism. Cell, 161, 93-105. (https://doi:10.1016/j.cell.2015.02.02)

Rehm, J., Mathers, C., Popova, S., Thavorncharoensap, M., Teerawattananon, Y., \& Patra, J. (2018). Global burden of disease and injury and economic cost attributable to alcohol use and alcohol-use disorders. The Lancet, 373, 2223-2233. (https://doi.org/10.1016/S0140-6736(09)60746-7)

Robertson, S. A. (2005). Seminal plasma and male factor signalling in the female reproductive tract. Cell and Tissue Research, 322, 43-52. (https://doi:10.1007/s00441-005-1127-3) 
Sansone, A., Di Dato, C., de Angelis, C., Menafra, D., Pozza, C., Pivonello, R., Isidori, A., \& Gianfrilli, D. (2018). Smoke, alcohol and drug addiction and male fertility. Reproductive Biology and Endocrinology, 16. (https://doi. org/10.1186/s12958-018-0320-7)

Sebastiani, G., Borrás-Novell, C., Casanova, M.A., Pascual Tutusaus, M., Ferrero Martínez, S., Gómez Roig, M.D., \& García-Algar, O. (2018). The effects of alcohol and drugs of abuse on maternal nutritional profile during pregnancy. Nutrients, 10, 1-17. (https://doi.org/10.3390/nu10081008)

Seed, J., Chapin, R. E., Clegg, E. D., Dostal, L. A., Foote, R. H., Hurtt, M. E., Klinefelter, G. R., Makris, S. L., Perreault, S. D., Schrader, S. et al. (1996). Methods for assessing sperm motility, morphology, and counts in the rat, rabbit, and dog: a consensus report. ILSI Risk Science Institute Expert Working Group on Sperm Evaluation. Reproductive Toxicology, 10, 237-244. (https://doi.org/10.1016/0890-6238(96)000287)

Sengupta, P., Borges, E., Dutta, S., \& Krajewska-Kulak, E. (2017). Decline in sperm count in European men during the past 50 years. Human \& Experimental Toxicology, 37(3), 247-255. (https://doi:10.1177/0960327117703690)

Sharlip, I. D., Jarow, J. P., Belker, A. M., Lipshultz, L. I., Sigman, M., Thomas, A. J., Schlegel, P. N., Howards, S. S., Nehra, A., Damewood, M.D., Overstreet, J. W., \& Sadovsky, R. (2002). Best practice policies for male infertility. Fertility and Sterility, 77, 873-882. (doi: 10.1016/s0015-0282(02)03105-9)

Smart, J.L., da Silva, V.A., Malheiros, L.R., Paumgartten, F.J., \& Massey, R.F. (1989). Epidermal growth factor advances some aspects of development but retards others in both rats and hamsters. Journal of Developmental Physiology, 11, 153-158.

Srivastava, V. K., Hiney, J. K., \& Dees, W. L. (2018). Alcohol delays the onset of puberty in the female rat by altering key hypothalamic events. Alcoholism: Clinical and Experimental Research, 42, 1166-1176. (https:// doi.org/10.1111/acer.13762)

Vaglenova, J., \& Petkov, V. V. (1998). Fetal Alcohol Effects in Rats Exposed Pre- and Postnatally to a Low Dose of Ethanol. Alcoholism: Clinical and Experimental Research, 22, 691-103.

Wallock-Montelius, L. M., Villanueva, J. A., Chapin, R. E., Conley, A. J., Nguyen, H. P., Ames, B. N., \& Halsted, C. H. (2007). Chronic Ethanol Perturbs Testicular Folate Metabolism and Dietary Folate Deficiency Reduces Sex Hormone Levels in the Yucatan Micropig1. Biology of Reproduction, 76(3), 455465. (https://doi:10.1095/biolreprod.106.053959)

Ward, I. L., Ward, O. B., Mehan, D., Winn, R. J., French, J. A., \& Hendricks, S. E. (1996). Prenatal alcohol and stress interact to attenuate ejaculatory behavior, but not serum testosterone or LH in adult male rats. Behavioral Neuroscience, 110, 1469-1477. (https://doi:10.1037/0735-7044.110.6.1469)

Witt, E. D. (2007). Puberty, hormones, and sex differences in alcohol abuse and dependence. Neurotoxicology and Teratology, 29(1), 81-95. (https://doi:10.1016/j.ntt.2006.10.013) 
Workman, J. L., Raineki, C., Weinberg, J., \& Galea, L. A. M. (2015). Alcohol and pregnancy: Effects on maternal care, HPA axis function, and hippocampal neurogenesis in adult females. Psychoneuroendocrinology, 57, 37-50. (https://doi:10.1016/j.psyneuen.2015.03.001)

Zi, Z., Zhang, Z., Li, Q., An, W., Zeng, L., Gao, D., \& Wu, J. (2015). CCNYL1, but Not CCNY, Cooperates with CDK16 to Regulate Spermatogenesis in Mouse. PLOS Genetics, 18, e1005485. (https://doi:10.1371/journal.pgen.1005485) 